\title{
KNOWLEDGE OF HIV/AIDS AND COVID-19 PANDEMIC AMONG DENTAL UNDERGRADUATE STUDENTS
}

\section{Dentistry}

Dr. Vaishnavi

Seetharaman*

Department of Orthodontics and Dentofacial Orthopaedics, Thai Moogambigai Dental College and Hospital, Dr. M.G.R Educational \& Research Institute, Golden George Nagar, Mogappair, Chennai 600107, Tamil Nadu. *Corresponding Author

Department of Orthodontics and Dentofacial Orthopaedics, Thai Moogambigai Dental Dr. Rajvikram. N College and Hospital, Dr. M.G.R Educational \& Research Institute, Golden George Nagar, Mogappair, Chennai 600107, Tamil Nadu.

Dr. Bharath Marlecha. R

Department of Orthodontics and Dentofacial Orthopaedics, Thai Moogambigai Dental College and Hospital, Dr. M.G.R Educational \& Research Institute, Golden George Nagar, Mogappair, Chennai 600107, Tamil Nadu.

Dr. Nandhini G. Ashok
Department of Orthodontics and Dentofacial Orthopaedics, Thai Moogambigai Dental College and Hospital, Dr. M.G.R Educational \& Research Institute, Golden George Nagar, Mogappair, Chennai 600107, Tamil Nadu.

\section{ABSTRACT}

Background: Within a century, COVID-19 is the 9th pandemic to worst hit the entire globe. The dental professionals are directly involved while treating patients in an aerosolized atmosphere.

Aim: To assess the knowledge of HIV/AIDS and COVID-19 pandemic among dental undergraduate students

Materials and Methods: A cross-sectional survey was conducted using a web-based survey instrument (google forms). A total of 366 dental undergraduate students of TMDCH, Chennai participated in the survey. Data obtained was analyzed using SPPS IBM Software.

Results: The knowledge on COVID-19 was better than HIV/AIDS, among the dental undergraduate students. Only $25.7 \%$ of the respondents had a previous experience of handling HIV positive case and just more than half (56.3\%) of the students were willing to treat HIV patient. Mere $25.7 \%$ agreed that HIV is a pandemic. For the COVID-19, only $45.6 \%$ of the students were confident to treat a positive/suspected patient and just $17.2 \%$ knew the types of corona virus. Knowledge on other questions asked was adequate. Dilemma prevailed if COVID-19 could cause diabetes and was air-borne.

Conclusion: There has to be an immediate intervention of the dental institutions to raise awareness on pandemics and their protocols while treatment of the patient among dental students through continuing education programs.

\section{KEYWORDS}

knowledge, dental students, undergraduate, HIV/AIDS, COVID-19, pandemic

\section{INTRODUCTION:}

It is no more hidden that there had been a total of 8 pandemics within a century and we are fighting the $9^{\text {th }}$ one currently- COVID-19, which has created a havoc in all folks of life. Currently, the toll hits to 19 million positive cases so far, throughout the globe and 2 million cases in India (as on 6 August 2020). COVID-19 was declared as a pandemic by the World Health Organization (WHO) on 11 March $2020^{1}$. From the Spanish flu (1919) to the Ebola outbreak (2014), it had millions of morbidity and mortality throughout the world ${ }^{2}$. The current COVID-19 does not break the rule either. What fascinating is HIV/AIDS outbreak (1980) which is still ongoing till date. There are more than 32 million positive HIV patients throughout the world, out of which, 1.7 million never knew until they were tested ${ }^{3}$. Every pathogen of any pandemic in the present or past has been very contagious, no doubt.

Dental students are directly or indirectly connected with epidemics and pandemics. The Dental Council of India (DCI) has circulated rules and regulations to be followed by the dental practitioners and students in the dental clinic set-up ${ }^{4}$. Since, COVID-19 can be transmitted directly by saliva or indirectly through aerosols mixed with saliva/blood ${ }^{5}$. On Contrary to HIV/AIDS, the possibility of its transmission in the oral health care set-up is very rare but the oral environment has proven to detect the earliest oral lesions associated with the initial stages of HIV infection. Willingness to treat patients with HIV/COVID-19 appears to be related to the knowledge of the disease process, modes of transmission, thus influencing health care workers attitudes and behavior towards management of such patient ${ }^{6}$. A sound basis of knowledge about HIV and COVID-19 infection is essential to allow students to develop as dentists who will undertake appropriate measures during their clinical practice?

Therefore, the aim of the study was to determine the knowledge among dental undergraduate students of Thai Moogambigai Dental College and hospital, Chennai (TMDCH) towards HIV and COVID-19 infection.

\section{MATERIALS AND METHODS:}

Study Population:

A cross-sectional survey was conducted using a web-based survey instrument (google forms). A total of 366 dental undergraduate students of TMDCH, Chennai participated in the survey. Ethical approval was obtained from the Institutional Review Board.

\section{Questionnaire:}

The designed questionnaire consisted of 20 questions, with the first 10 questions aiming to gauge the awareness of COVID-19 and the next 10 questions on HIV/AIDS, among the dental undergraduate students. Both the set of questions were close-ended and made compulsory to answer. The survey material was passed on to the study population using multiple social media platforms and the responses were recorded simultaneously.

\section{Statistical Analysis:}

Data obtained was entered in the Microsoft Excel and was imported to SPPS IBM Software Tool (Version 19, IBM Chicago) for statistical analysis.

\section{RESULTS:}

The results obtained from the survey material were descriptive in nature. From the results obtained, it was clear that the dental undergraduate students had a better knowledge on COVID-19 over HIV/AIDS. Only half $(50.5 \%)$ of the study population knew the types of HIV that dominates the globe [Table 2] while only $17.2 \%(n=63)$ answered right for the types of COVID-19 [Table 1]. It is surprising that over $74.3 \%(n=272)$ of the students, still disagree that HIV/AIDS is a pandemic. Over $56.3 \%(n=206)$ answered that they were confident to treat HIV/AIDS patient while $45.6 \%(n=167)$ were confident for treating COVID-19 positive/suspected patients [Table 3]. Mere, $25.7 \%(n=94)$ of dental undergraduate students had a past experience to handle a known case of HIV/AIDS. Dilemma prevailed when questions, if COVID-19 causes diabetes or is airborne, was asked [Table 3]. Further, correct responses to other questions on COVID-19 
[Table 1] and to questions on HIV/AIDS [Table 2] are given below.

TABLE 1: Responses to questions on COVID-19:

\begin{tabular}{|c|c|c|}
\hline \multicolumn{3}{|c|}{ RESPONSES TO QUESTIONS ON COVID - 19 } \\
\hline 1 & $\begin{array}{c}\text { Number } \\
\text { QUESTION (Correct response) } \\
\text { responded in \% }\end{array}$ \\
\hline 2 & Types of Corona Virus (FOUR TYPES) & 92.1 \\
\hline 3 & COVID-19 patients treated in separate wards & 17.2 \\
\hline 4 & (YES) & 95.9 \\
\hline 5 & $\begin{array}{c}\text { PPE required for examining suspected patient } \\
\text { (YES) }\end{array}$ & 81.7 \\
\hline 6 & Diarrhoea is a symptom (YES) & 69.4 \\
\hline 7 & Antibiotics are the first line of treatment (NO) & 49.2 \\
\hline
\end{tabular}

TABLE 2: Responses to questions on HIV/AIDS

\begin{tabular}{|c|c|c|}
\hline \multicolumn{3}{|c|}{ RESPONSES TO QUESTIONS ON HIV } \\
\hline & QUESTION (Correct Response) & $\begin{array}{c}\text { Number } \\
\text { responded in \% }\end{array}$ \\
\hline 1 & Saliva, route of transmission of HIV (NO) & 52.2 \\
\hline 2 & Types of HIV (TWO TYPES) & 50.5 \\
\hline 3 & HIV is curable (YES) & 50.5 \\
\hline 4 & Vaccine for HIV (NO) & 85.2 \\
\hline 5 & Does HIV mutate (YES) & 70.5 \\
\hline 6 & HIV is fully preventable (YES) & 59.6 \\
\hline 7 & PPE required for examining a suspected & 57.1 \\
\hline 8 & HIV/AIDS patient (NO) & 25.7 \\
\hline
\end{tabular}

\section{TABLE 3: Responses to attitude-based questions}

\begin{tabular}{|c|c|c|c|c|c|}
\hline \multirow{2}{*}{ Question } & \multicolumn{2}{|c|}{ Agee } & \multicolumn{2}{c|}{ Disagree } \\
\cline { 2 - 6 } & & $\mathbf{n}$ & $\mathbf{0}$ & $\mathbf{n}$ & $\mathbf{\%}$ \\
\hline Covid - 19 & Causes diabetes & 68 & $18.9 \%$ & 298 & $81.8 \%$ \\
\cline { 2 - 6 } & Is airborne & 200 & $79.1 \%$ & 76 & $20.9 \%$ \\
\cline { 2 - 6 } & $\begin{array}{c}\text { Confident to treat a } \\
\text { suspected/positive patient }\end{array}$ & 167 & $45.6 \%$ & 199 & $54.4 \%$ \\
\hline HIV/Aids & $\begin{array}{c}\text { Previous experience of } \\
\text { treating a positive patient }\end{array}$ & 94 & $25.7 \%$ & 272 & $74.3 \%$ \\
\cline { 2 - 6 } & $\begin{array}{c}\text { Confident to treat a } \\
\text { suspected / positive } \\
\text { patient }\end{array}$ & 206 & $56.3 \%$ & 160 & $43.7 \%$ \\
\hline
\end{tabular}

\section{DISCUSSION:}

It is very important to assess the level of awareness in the dental undergraduate students regarding COVID-19 and HIV/AIDS. Both of these pandemics are contagious, if necessary, precautions aren't followed meticulously, this can lead to cross-transmission of the infection

The awareness on HIV was fair among the dental undergraduate students. The transmission of HIV/AIDS through oral environment is very rare. HIV particles are found in saliva but they are non-contagious as only protein remnants of the virus are present ${ }^{8}$. More than half of the dental students agreed to this question in the present study. The knowledge on the salivary transmission of HIV/AIDS is very important to be imparted to the students as this will reflect in the attitude of willingness to treat a HIV/AIDS positive patient. In the present study, only half of the total respondents were willing to treat a HIV/AIDS positive patient. The HIV which is still dominating the globe, is of two types: HIV-1 and HIV-2. Most common amongst it is HIV-1 whereas HIV-2 is less contagious and is only confined to West Africa $^{9}$. More than half of the participants responded it right to this question, in the present study. Since the HIV mutates very quick and takes over the immune system and curbs CD4+T cells, there is no vaccine in the market currently, yet trials of the vaccine are ongoing $^{10,11}$. Majority of the students agreed to both of these facts in the current study. According to WHO, HIV is fully preventable when necessary precautions are followed by the individual, of which, safe sexual practice is very important. Condoms are to be used with unknown partners and it is wise to avoid multiple partners. Sterilized needles should be used in the hospitals to avoid the risk of its transmission $^{12}$. HIV/AIDS is not curable yet there are medicines which is only for symptomatic relief. Retro-viral drugs are available but the

drug only decreases the load of the virus in the blood and body but does not eradicate it completely ${ }^{13}$. Personal Protective Equipment (PPE) is required only when handling bodily fluids of HIV positive patients. For mere examination of such patients there is no requirement of a full PPE. A pair of disposable gloves and disposable surgical mask is more than sufficient. While treating a patient in a dental set-up, it is mandatory to use a full PPE as there is a high risk for transmission in the aerosols mixed with blood ${ }^{14}$. It is widely accepted by many authors that HIV is a pandemic as it has affected more than 32 million people throughout the world ${ }^{15}$. A very low number of students agreed to this, in the present study. Dental students have to be exposed to HIV cases or made to assist, to familiarize with the protocols to be followed and to eradicate the fear in them about the disease. In the current study only a quarter of the participants had a previous experience of handling/examining a known case of HIV patient.

In a contrary, the dental undergraduate students had a better knowledge on COVID-19. It is supported with many evidences that COVID-19 can be transmitted through the saliva and this poses a great risk to the dental professionals as they are most of the times exposed to aerosolized atmosphere while treating a patient. A majority of the students had sufficient knowledge on this fact. Currently, there are four genera/ types of coronaviruses: $\alpha-\mathrm{CoV}$ and $\beta-\mathrm{CoV}$ infect the humans and mammals whereas $\gamma-\mathrm{CoV}$ and $\delta$-CoVinfect the birds ${ }^{16}$. Knowledge on this was found to be poor among the dental students in the current study. It is definite that COVID-19 patients are treated in separate wards as it is very contagious. It is transmitted through either direct or indirect contact. According to Centers for Disease Control and Prevention (CDC), it is mandatory to wear PPE while treating suspected/positive COVID-19 patient ${ }^{17}$. The PPE includes: Disposable gloves, N95 mask, Gown, Face shield, protective eye wear. Corona virus undoubtedly mutates. In specific, the spike protein is the mutation hotspot ${ }^{18}$. The symptoms of the COVID19 vary ranging from mild to severe and in some cases the disease can be fatal. Symptoms typically include fever, dry cough, shortness of breath, fatigue, muscle pain, headache, itchy/sore throat, diarrhoea and vomiting ${ }^{19}$. Antibiotics are not the first line treatment for a viral infection like COVID-19. Antibiotics are given only if there is a bacterial infection associated with COVID-19 $9^{20}$. There is a progressing knowledge that COVID-19 causes new-onset diabetes in patients as it causes dysfunction in glucose metabolism. Yet, the co-relation is under research ${ }^{21}$. In the present study, a majority of the dental students disagreed to this statement. It is strongly recommended that COVID-19 is air-borne and the virus particles lingers in the droplets/aerosols amidst the closed indoors. The information was passed by the scientists to the WHO to reconsider the precautions and protocols it had released ${ }^{22}$. A majority of the population in the current study had agreed to this dilemma which is yet to be studied. More than half of the dental students had agreed to not have confident in handling a positive/suspected COVID-19 patient. In a previous study done among dental practitioners, it was found that they lacked adequate knowledge on the treatment protocols to be followed amidst the COVID- $19^{23}$. It is thus imperative that every practitioner including students should update with the information what authoritative organizations release.

\section{CONCLUSION:}

As HIV/AIDS and COVID-19 continue to prevail, it is of utmost importance to educate and provide adequate exposure to dental undergraduate students to be able to treat and manage affected individuals with necessary precautionary measures. The curriculum of the undergraduate course in dentistry across the nation should be modified and updated with comprehensive material in order to professionally equip the dental students, so that they are better placed in treating such patients with no discrimination and stigma prevailing in the society and during the sustenance of the two pandemics.

\section{LIMITATIONS:}

The current study was done amidst the lockdown through google survey forms among the students at home. The study has not performed inferential statistics as it was difficult to gather different comparative groups based on the year of study. A lot more detailed questionnaire has to framed in the future studies to further conclude the knowledge among the students.

\section{Conflicts Of Interest: -nil-}

\section{REFERENCES:}

Cucinotta D, Vanelli M. WHO declares COVID-19 a pandemic. Acta bio-medica: Atenei Parmensis. 2020 Mar 19:91(1):157-60. 
2. Pittman KJ, Glover LC, Wang L, Ko DC. The legacy of past pandemics: common human mutations that protect against infectious disease. PLoS pathogens. 2016 Jul 21;12(7): e1005680.

3. Johnson AM. Condoms and HIV transmission.

4. Chugh R, Chugh V, Lamba A, Shah Y, Mukherjee J, Muchhala S, et al. Indian Dental Association. New Delhi: Dental Council of India; 2020

5. Rothan HA, Byrareddy SN. The epidemiology and pathogenesis of coronavirus disease (COVID-19) outbreak. Journal of autoimmunity. 2020 Feb 26:102433.

6. Erasmus S, Luiters S, Brijlal P. Oral hygiene and dental students' knowledge, attitude and behavior in managing HIV/AIDS patients. Int J Dent Hyg. 2005 .3(4) :213-217.3

7. Seacat JP, Inglehart MS, Habil P. Education about treating patients with HIV infections/AIDS: the student perspective. J Dent Educ.2003; 67: 630-639.

8. Campo J, Perea MA, Del Romero J, Cano J, Hernando V, Bascones A. Oral transmission of HIV, reality or fiction? An update. Oral diseases. 2006 May;12(3):219-28.

9. Takehisa J, Zekeng L, Ido E, Mboudjeka I, Moriyama H, Miura T, Yamashita M, Gürtler LG, Hayami M, Kaptué L. Various types of HIV mixed infections in Cameroon. Virology. 1998 May 25;245(1):1-0

10. Davenport MP, Loh L, Petravic J, Kent SJ. Rates of HIV immune escape and reversion: implications for vaccination. Trends in microbiology. 2008 Dec 1;16(12):561-6.

11. Nowak M. HIV mutation rate. Nature. 1990 Oct 11;347(6293):522-

12. Sepúlveda C, Marlin A, Yoshida T, Ullrich A. Palliative care: The World Health Organization's global perspective. Journal of pain and symptom management. 2002 Aug 1;24(2):91-6.

13. Hamer DH Can HIV be cured? Mechanisms of HIV persistence and strategies to combat it. Current HIV research. 2004 Apr 1;2(2):99-111.

14. Araujo MW, Andreana S. Risk and prevention of transmission of infectious diseases in dentistry. Quintessence international. 2002 May 1;33(5).

15. Quinn TC. Global burden of the HIV pandemic. The lancet. 1996 Jul 13;348(9020):99106.

16. Peng X, Xu, Li Y, Cheng L, Zhou X, Ren B. Transmission routes of 2019-nCoV and controls in dental practice. Int J Oral Sci. 2020;12(1):9.

17. Livingston E, Desai A, Berkwits M. Sourcing personal protective equipment during the COVID-19 pandemic. Jama. 2020 May 19;323(19):1912-4.

18. Banerjee AK, Begum F, Ray U. Mutation Hot Spots in Spike Protein of COVID-19.

19. Huang C, Wang Y, Li X, Ren L, Zhao J, Hu Y, et al. Clinical features of patients infected with 2019 novel coronavirus in Wuhan, China. Lancet Lond Engl. 2020;395(10223):497-506.

20. Rawson TM, Moore LS, Zhu N, Ranganathan N, Skolimowska K, Gilchrist M, Satta G, Cooke G, Holmes A. Bacterial and fungal co-infection in individuals with coronavirus: A rapid review to support COVID-19 antimicrobial prescribing. Clinical Infectious Diseases. 2020 May 2

21. Singh AK, Gupta R, Ghosh A, Misra A. Diabetes in COVID-19: Prevalence, pathophysiology, prognosis and practical considerations. Diabetes \& Metabolic Syndrome: Clinical Research \& Reviews. 2020 Apr 9.

22. Morawska L, Milton DK. It is time to address airborne transmission of COVID-19. Clinical Infectious Diseases. 2020 Jul 6;7.

23. Ashok NG, Devadoss P, Aishwarya K, Marlecha RB. Knowledge of dental practitioners toward the treatment protocol given by the Dental Council of India during COVID-19 pandemic in Chennai. Drug Invention Today. 2020 Jul 15;14(7). 